\title{
Preliminary Study of Gastroprotective Effect of Aloe perryi and Date Palm Extracts on Pyloric Ligation-Induced Gastric Ulcer in Experimental Rats
}

\author{
Naif Al-Gabri $\mathbb{D}^{1,2}$ Gehad M. Elnagar $\mathbb{D}^{3},{ }^{3}$ Sultan A. M. Saghir $\mathbb{D}^{4},{ }^{4}$ Amina El-Shaibany $\mathbb{D}^{1},{ }^{5}$ \\ Sultan F. Alnomasy ${ }^{6},{ }^{6}$ Ziyad M. Althafar $\mathbb{D},{ }^{6}$ Nesreen M. I. M. Elkomy, ${ }^{7}$ \\ Mahmoud M. Elaasser $\odot{ }^{8},{ }^{8}$ Maisa Siddiq Abdoh, ${ }^{9,10}$ and Mohammed Yosri $\oplus^{8}$ \\ ${ }^{1}$ Veterinary Department, Faculty of Agriculture and Veterinary Medicine, Thamar University, Dhamar, Yemen \\ ${ }^{2}$ Laboratory of Salam Veterinary Group, Buraydah, Al-Qassim, Saudi Arabia \\ ${ }^{3}$ Biochemistry Department, Faculty of Pharmacy, Zagazig University, Zagazig 44519, Egypt \\ ${ }^{4}$ Department of Medical Analysis, Princess Aisha Bint Al Hussein College of Nursing and Medical Analysis, Al-Hussein Bin \\ Talal University, Ma'an, Jordan \\ ${ }^{5}$ Pharmacognosy Department, University of Sana'a, Pharmacy College, Yemen \\ ${ }^{6}$ Department of Medical Laboratories Sciences, College of Applied Medical Sciences in Al-Quwayiyah, Shaqra University, Al- \\ Quwayiyah, Riyadh, Saudi Arabia \\ ${ }^{7}$ Department of Pharmacology and Toxicology, Faculty of Pharmacy, Zagazig University, Egypt \\ ${ }^{8}$ The Regional Center for Mycology and Biotechnology, Al-Azhar University, 11787 Nasr City, Cairo, Egypt \\ ${ }^{9}$ Department of Medical Laboratory Sciences, Faculty of Applied Medical Sciences, King Abdulaziz University, Jeddah, Saudi Arabia \\ ${ }^{10}$ Center of Excellence in Genomic Medicine Research, King Abdulaziz University, Jeddah, Saudi Arabia
}

Correspondence should be addressed to Mohammed Yosri; mohammed.yosri@yahoo.com

Received 4 November 2021; Revised 11 December 2021; Accepted 27 December 2021; Published 24 January 2022

Academic Editor: Ahmet Özer Sehirli

Copyright (C) 2022 Naif Al-Gabri et al. This is an open access article distributed under the Creative Commons Attribution License, which permits unrestricted use, distribution, and reproduction in any medium, provided the original work is properly cited.

Objective. The present study was aimed at investigating the possible antiulcer activities of some natural phytochemicals Aloe perryi leaf extract (APLE) and flower extract (APFE) in addition to the date palm seed extract (DPSE) and the oily samples of DPSE in a pylorus ligation-induced ulcer model using ranitidine as a standard antiulcer drug. Background. Peptic ulcer is a prevalent gastrointestinal disorder due to hypersecretion of gastric acid. It affects four million people worldwide, and 2-10\% of these ulcers are perforated and cause bleeding. This increases the risk of morbidity and mortality. So we aimed to introduce a primary study alternatively safe method for treating peptic ulcer. Materials and Methods. Forty-two Wistar Albino rats of either sex were randomly divided into seven groups (6/each). The pylorus ligation was done to induce ulcer in pretreated albino rats. The antiulcer activities of extracts were estimated at different dose levels (250 and $500 \mathrm{mg} / \mathrm{kg})$ using ranitidine as a standard drug $(50 \mathrm{mg} / \mathrm{kg})$. Gastric volume, $\mathrm{pH}$, and total and free acidity as well as ulcer index and percentage of ulcer inhibition were measured to elucidate the antiulcerogenic effects. Histological examination of gastric ulcer was also performed. Statistical analysis for the results was done where $P<0.05$ was considered statistically significant. Results. Pylorus ligation for $6 \mathrm{~h}$ in control rats resulted in gastric ulcer which was indicated by the accumulation of gastric secretion and increased total acidity and decreased $\mathrm{pH}$. The pretreatment of rats with APLE, APFE, and DPSE in addition to the oily samples of DPSE significantly inhibited the ulcers induced by pylorus ligation. These effects were attributed to significant reductions in total and free acidity, ulcer index, and gastric volume while there is a marked decrease in gastric $\mathrm{pH}$ (the antisecretory) as well as mucosal strengthening properties of these phytochemicals. Conclusion. These findings give these extracts the potential to be a promising tool for the management of gastric ulcer after performing further clinical and experimental studies. Our study demonstrated the promising antiulcer activity of extracts and oils in pyloric ligation-induced gastric ulcer. To the best of our knowledge, this is the first study to explore the antiulcer activity of these extracts; however, further investigations may be recommended for full details about this antiulcerogenic capacity. 


\section{Introduction}

The peptic ulcer is considered a worldwide chronic disease affecting millions of people and therefore associated with a higher rate of morbidity and mortality [1]. Many factors are contributing to the development of peptic ulcer such as stress, dietary factors, high production of acid, helicobacter Pylori infection, and the use of nonsteroidal antiinflammatory drugs [2]. Peptic ulcer results in damage of protective mucosal lining of the stomach and duodenum leading to the ulcerogenic process [3].

The treatment of peptic ulcer mainly depended on using remedies that reduce gastric acid secretion such as antacid, but in the last two decades, new drugs are used like an $\mathrm{H} 2$ antagonist and proton pump inhibitors. Ranitidine is an $\mathrm{H} 2$ receptor antagonist that competes reversibly with histamine for $\mathrm{H} 2$ receptor binding on the basolateral membrane of parietal cells thus inhibiting the secretion of gastric acid. It is the most commonly prescribed drug for treating many gastrointestinal disorders such as peptic ulcer and gastroesophageal reflux disease [4]. Ranitidine is a standard antiulcer drug used in many previous studies of gastric ulcer experimentally induced by pyloric ligation in animal models [5-9].

However, the wide use of these antiulcer medications has many drawbacks such as cost, toxicity, drug-drug interactions, and upsetting some cardiac diseases. Therefore, an attention is paid to find more safe and potent nontoxic drugs. Among these new remedies are the herbal drugs due to their lower cost and side effects as well as easy availability $[10,11]$.

Aloe perryi (Zanzibar or Socotrine aloe) is localized in Socotra in Yemen, an island east of Somalia. It is rich in many active pharmacological compounds like minerals, lectins, vitamins, glycoprotein, alkaloids, amino acids, anthraquinone glycosides, and many essential oils responsible for various medicinal uses of Aloe perryi such as anticancer, antibacterial, analgesic, anti-inflammatory, antitumor, antimicrobial, and antiviral activities [12]. Its effect in healing wounds and burns was also reported [13]. Mothana et al. revealed the use of Aloe perryi to combat eye and malaria infections and gastrointestinal disorders such as constipation [14].

Date palm (Phoenix dactylifera) is considered an important herbal product used in traditional medicines for its potential benefits for health. Egypt is one of the countries that produce date palm [15]. The palm date seed extract is a good source of various important compounds such as saturated and unsaturated fatty acids, phenolic compounds, tocopherols, and sterols which give the extract valuable properties like antiviral, antioxidant, anticancer, antimicrobial, and hypoglycemic ones [16].

Therefore, this study is aimed at introducing a safe medication for treating peptic ulcer versus using the wellestablished standard antiulcer drug.

\section{Materials and Methods}

2.1. Preparation of Plant Extracts. A plant taxonomist in the Department of Botany, Faculty of Science, Sana'a University, Yemen, authenticated both Aloe perryi and date palm seeds. Voucher specimens $(\# 4469,4467)$ were deposited in the herbarium of the Pharmacognosy Department, Sana'a University.

2.1.1. Aloe perryi Extract. The fresh flowers and green leaves of $A$. perryi were collected during the flowering stage in June to July 2019 from the island of Socotra, Yemen.

Both plant parts were dried under shade, powdered coarsely, and stored in an airtight container. The powdered Aloe perryi flowers and leaves were $0.5 \mathrm{~kg}$ each of them and then were extracted with ethanol $(3 \times 101)$ at room temperature using a cold maceration procedure. The combined ethanol extract was concentrated under reduced pressure using a rotary evaporator to obtain a thick dark greenish gummy mass for leaves and a reddish brown semisolid extract for the flowers [17].

2.1.2. Date Palm Seed Extract. Date fruits were collected during the last stage of the ripening process in Hadhramaut City, Yemen, 2019. Seeds were isolated from fruits, then soaked in hot water, and washed to remove any adhered date flesh. The seeds were oven dried at $60^{\circ} \mathrm{C}$ for a day and then roasted and ground using a mechanical grinder to form a powder followed by a sieving process [18].

2.1.3. Preparation of the Oily Samples of the Date Palm Seed Extract. To get yellow colored oil, five hundred grams $(500 \mathrm{~g})$ of powdered seed of Phoenix dactylifera was extracted exhaustively with 51 of methanol while to get red colored oil, three hundred grams $(300 \mathrm{~g})$ of powdered seed of Phoenix dactylifera was extracted exhaustively with 31 of hexane. The combined filtrates from each one were evaporated by using a rotary evaporator to get the concentrated crude dark brown seed extract; then, oil is leached out from the seed extract where it is separated and purified by filtration.

2.1.4. Transfer to Powder. All stock solution extracts were prepared in dimethyl sulfoxide (DMSO) due to incomplete dissolving in aqueous solution.

2.2. Chemicals and Drugs. Ranitidine was obtained from India (Kopran Pharma Ltd., Mumbai). All chemicals or solvents utilized in this study are of analytical grade and supplied from Sigma-Aldrich Chemical Company (St. Louis, MO, USA).

2.3. Animals. Forty-two Wistar albino rats weighing 150$200 \mathrm{~g}$ of either sex (8-10 weeks of age) were purchased from the Faculty of Veterinary Medicine, Sana'a University, and maintained under standard husbandry conditions (temp 23 $\pm 2^{\circ} \mathrm{C}$, relative humidity $55 \pm 10 \%$, and 12 -hour light-dark cycle). Animals were fed with standard laboratory food ad libitum during the study period. All experiments were approved by the institutional Ethical Committee, Faculty of Medicine and Health Sciences, Sana'a University (\#no.125$10 / 3 / 2019 \#)$, following the standard guidelines for the use of laboratory animals.

2.4. Experimental Design. Albino rats of either sex were randomly divided into seven groups of six animals each as follows:

(i) Group 1: control group: rats received only distilled water before one hour from pyloric ligation 
TABLE 1: The ulcer protective effect of the A. perryi leaf extract (APLE) and ranitidine on the pylorus ligation-induced ulcer model in the experimental rat model.

\begin{tabular}{lcccccc}
\hline Treatment & Dose & Gastric volume $(\mathrm{ml})$ & $\mathrm{pH}$ & Total acidity $(\mathrm{mEq} / \mathrm{l})$ & Free acidity (mEq/l) & Ulcer index \\
\hline Control & $1 \mathrm{ml} / \mathrm{kg}$ & $8.47 \pm 0.15$ & $3.21 \pm 0.13$ & $120.83 \pm 2.20$ & $94.32 \pm 0.31$ & $3.58 \pm 0.09$ \\
\multirow{2}{*}{ APLE } & $250 \mathrm{mg} / \mathrm{kg}$ & $4.38 \pm 0.11$ & $4.47 \pm 0.17^{*}$ & $76.33 \pm 1.17^{*}$ & $65.67 \pm 1.20^{*}$ & $2.15 \pm 0.05^{*}$ \\
& $500 \mathrm{mg} / \mathrm{kg}$ & $3.40 \pm 0.07^{\mathrm{a}}$ & $5.12 \pm 0.11^{*}$ & $66.83 \pm 1.58^{*}$ & $43.83 \pm 1.22^{*}$ & $1.34 \pm 0.14^{\wedge}$ \\
Ranitidine & $50 \mathrm{mg} / \mathrm{kg}$ & $4.25 \pm 0.21^{*}$ & $5.35 \pm 0.15^{*}$ & $37.0 \pm 0.17^{*}$ & $17.0 \pm 0.24^{*}$ & $1.00 \pm 0.03^{*}$ \\
\hline
\end{tabular}

Control: rats received only distilled water; APLE: rats received the Aloe perryi leaf extract in a dose level (250 and $500 \mathrm{mg} / \mathrm{kg})$ (p.o.); ranitidine: rats received ranitidine which is dissolved in distilled water and given in a dose level $(50 \mathrm{mg} / \mathrm{kg})$ (p.o.) and served as a standard drug. $n=6 /$ group. Values are expressed as mean $\pm \operatorname{SEM}(n=6) .{ }^{*} P$ value is $<0.001,{ }^{\text {a }} P$ value is $<0.01$, and $\wedge P$ value is $<0.05$ versus control.

(ii) Group 2: ranitidine group: rats received ranitidine which is dissolved in distilled water and given in a dose level $(50 \mathrm{mg} / \mathrm{kg})$ (p.o.) and served as a standard drug before one hour from pyloric ligation

(iii) Group 3*: A. perryi leaf extract group (APLE): rats received the Aloe perryi leaf extract in dose levels of 250 and $500 \mathrm{mg} / \mathrm{kg}$ (p.o.) before one hour from pyloric ligation

(iv) Group 4*: A. perryi flower extract group (APFE): rats received the Aloe perryi flower extract in dose levels of 250 and $500 \mathrm{mg} / \mathrm{kg}$ (p.o.) before one hour from pyloric ligation

(v) Group 5*: date palm seed extract group (DPSE): rats received the date palm seed extract in dose levels of 250 and $500 \mathrm{mg} / \mathrm{kg}$ (p.o.) before one hour from pyloric ligation

(vi) Group 6*: yellow oil group: rats received date yellow oil in dose levels of 250 and $500 \mathrm{mg} / \mathrm{kg}$ (p.o.) before one hour from pyloric ligation

(vii) Group 7*: red oil group: rats received date red oil in dose levels of 250 and $500 \mathrm{mg} / \mathrm{kg}$ (p.o.) before one hour from pyloric ligation

Asterisks in groups 3, 4, 5, 6, and 7 indicate that animals were divided into two subgroups to receive two dose levels $(250$ and $500 \mathrm{mg} / \mathrm{kg}$ ) of different tested extracts.

2.5. Induction of Gastric Ulcer by Pyloric Ligation. The ulcer was induced by the pyloric ligation method of Shay [19]. Rats were fasted for $24 \mathrm{~h}$ before operation, in individual cages. After $1 \mathrm{~h}$ of drug treatment, they were anesthetized with the help of anesthetic ether; the abdomen was opened by a small midline incision below the xiphoid process. Pyloric portion of the stomach was slightly lifted out and ligated, avoiding traction to the pylorus or damage to its blood supply. The stomach was replaced carefully, and the abdominal wall was closed by interrupted sutures. Rats were sacrificed by an over dose of anesthetic ether after four hours of pyloric ligation. The abdomen was opened, the cardiac end of the stomach was dissected out, and the contents were drained into a glass tube.

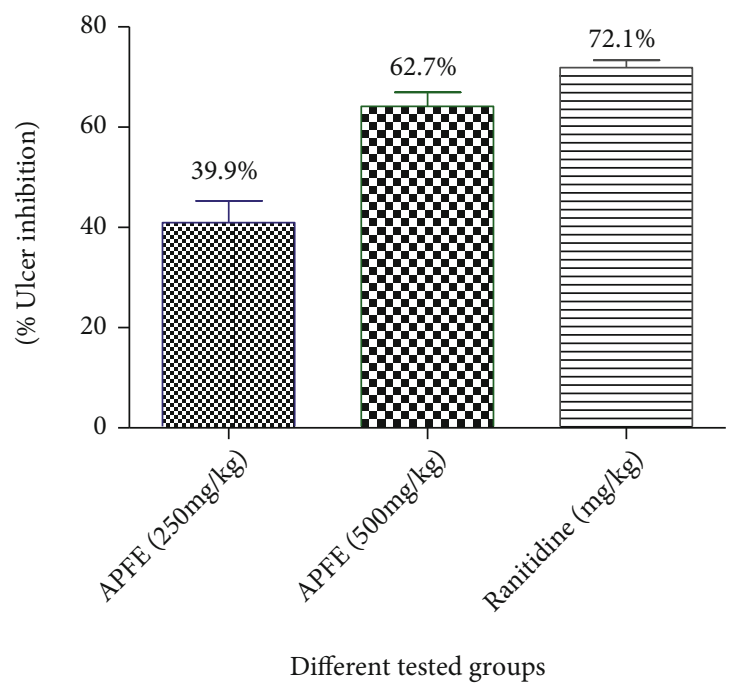

Figure 1: Effect of the A. perryi leaf extract (APLE) and ranitidine on the percentage of ulcer inhibition in the pylorus ligationinduced ulcer model in the experimental rat model. APLE: rats received the Aloe perryi leaf extract in a dose level (250 and $500 \mathrm{mg} / \mathrm{kg}$ ) (p.o.); ranitidine: rats received ranitidine which is dissolved in distilled water and given in a dose level $(50 \mathrm{mg} / \mathrm{kg})$ (p.o.) and served as a standard drug. $n=6 /$ group.

The volume of the gastric juice was measured and centrifuged at $2000 \mathrm{rpm}$ for $10 \mathrm{~min}$. From the supernatant, aliquots ( $1 \mathrm{ml}$ of each) were taken for the determination of $\mathrm{pH}$ and total and free acidity. Each stomach was examined for lesions in the forestomach portion and indexed according to severity.

2.6. The $\mathrm{pH}$ Measurement. A pH meter is used for determining $\mathrm{pH}$ after diluting $1 \mathrm{ml}$ of gastric juice aliquot with $1 \mathrm{ml}$ of distilled water.

2.7. The Total and Free Acidity Determination. $1 \mathrm{ml}$ of distilled water was used to dilute $1 \mathrm{ml}$ of gastric juice aliquot and then transferred to a conical flask $(50 \mathrm{ml})$ with the addition of 2 drops of phenolphthalein indicator (Topfer's reagent for the determination of free acidity). $0.01 \mathrm{NaOH}$ was used for titration until a permanent pink color (canary 
TABLE 2: The ulcer protective effect of the A. perryi flower extract (APFE) on the pylorus ligation-induced ulcer model.

\begin{tabular}{|c|c|c|c|c|c|c|}
\hline Treatment & Dose & Gastric volume (ml) & $\mathrm{pH}$ & $\begin{array}{c}\text { Parameters } \\
\text { Total acidity }(\mathrm{mEq} / \mathrm{l})\end{array}$ & Free acidity $(\mathrm{mEq} / \mathrm{l})$ & Ulcer index \\
\hline Control & $1 \mathrm{ml} / \mathrm{kg}$ & $8.47 \pm 0.15$ & $3.21 \pm 0.13$ & $120.83 \pm 2.20$ & $94.32 \pm 0.31$ & $3.58 \pm 0.09$ \\
\hline \multirow{2}{*}{ APFE } & $250 \mathrm{mg} / \mathrm{kg}$ & $3.62 \pm 0.21^{\wedge}$ & $5.52 \pm 0.11^{*}$ & $93.17 \pm 1.30^{*}$ & $84.00 \pm 1.18^{*}$ & $1.69 \pm 0.03^{*}$ \\
\hline & $500 \mathrm{mg} / \mathrm{kg}$ & $2.32 \pm 0.12^{*}$ & $6.73 \pm 0.12^{*}$ & $65.33 \pm 1.38^{*}$ & $48.67 \pm 2.59^{*}$ & $1.01 \pm 0.03$ \\
\hline Ranitidine & $50 \mathrm{mg} / \mathrm{kg}$ & $4.25 \pm 0.21^{*}$ & $5.35 \pm 0.15^{*}$ & $37.0 \pm 0.17^{*}$ & $17.0 \pm 0.24^{*}$ & $1.00 \pm 0.03^{*}$ \\
\hline
\end{tabular}

Control: rats received only distilled water; APFE: rats received the Aloe perryi flower extract in a dose level (250 and $500 \mathrm{mg} / \mathrm{kg}$ ) (p.o.); ranitidine: rats received ranitidine which is dissolved in distilled water and given in a dose level (50 mg/kg) (p.o.) and served as a standard drug. $n=6 /$ group. Values are expressed as mean $\pm \operatorname{SEM}(n=6) .{ }^{*} P$ value is $<0.001$ and $\wedge P$ value is $<0.05$ versus control.

yellow color for free acidity) was resulted; its consumed volume was determined. The total acidity is expressed as $\mathrm{mEq} / \mathrm{l}$ by calculating according to Reddy et al.'s formula [20].

2.8. Macroscopic Evaluation of Gastric Ulcer. A 10x magnifier lens was used to evaluate the ulcers after opening the stomachs along the greater curvature and rinsing them with saline to eliminate any gastric contents or blood clots. For quantification scores, analysis depended on mucosal color, hemorrhages, and superficial and deep ulcer besides perforation which were numbered as follows: $0=$ no changes, $1=$ mild or focal, $2=$ mild to moderate, and $3=$ severe [20].

2.9. Histological Examination of the Stomach. A portion of the ulcerated stomach was dissected out and fixed in $10 \%$ buffered neutral formalin solution; then, tissues were embedded in paraffin, and solid sections were cut at $5 \mu \mathrm{m}$ by using a LICA microtome and stained with routine hematoxylin and eosin (H\&E). The sections were examined under a light microscope and photomicrographs were taken, and lesion scores were compared according to the following semiquantification assay: $0=$ normal appearance, $0.5=$ mild changes, $1=$ moderate changes, $1.5=$ severe changes, $2=$ over severity, and $3=$ diffused [21].

2.10. Statistical Analysis. Results were expressed as mean \pm SEM. The significance of association between means was assessed by one way-ANOVA, and the group means were evaluated by Dunnett's post hoc test using the SPSS program version $21 . P<0.05$ was considered statistically significant.

\section{Results}

3.1. Antiulcer Activity of DMSO Solution of the A. perryi Leaf Extract (APLE) and Ranitidine in Experimental Rats. The treatment of animals with APLE at $250 \mathrm{mg} / \mathrm{kg}$ and $500 \mathrm{mg} /$ $\mathrm{kg}$ produced significant reductions in total and free acidity and ulcer index while gastric volume was significantly different only on using the high dose of this extract $(P<0.01) ; \mathrm{pH}$ of the gastric juice was increased as compared to the ulcer control group. Ranitidine resulted in more reduction in the gastric parameters $(P<0.001)$ when compared to the control. The ulcer index demonstrated a higher ulcer inhibition with ranitidine therapy $(72.1 \%)$ when compared with APLE (39.9\% and 62.7\%) (Table 1/Figure 1).

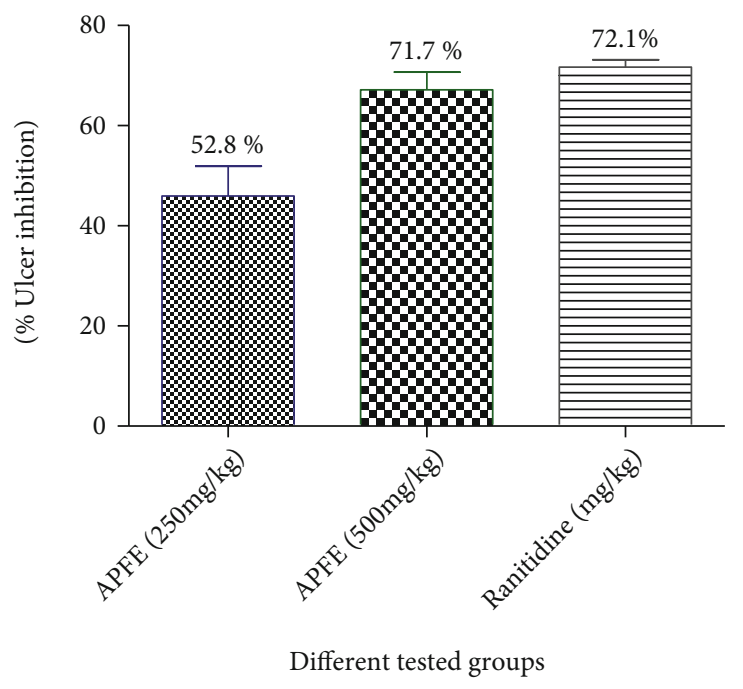

FIgURe 2: Effect of the $A$. perryi flower extract (APFE) and ranitidine on the percentage of ulcer inhibition in the pylorus ligation-induced ulcer model in the experimental rat model. APFE: rats received the Aloe perryi flower extract in a dose level (250 and $500 \mathrm{mg} / \mathrm{kg}$ ) (p.o.); ranitidine: rats received ranitidine which is dissolved in distilled water and given in a dose level (50 mg/kg) (p.o.) and served as a standard drug. $n=6 /$ group.

3.2. Antiulcer Activity of DMSO Solution of the A. perryi Flower Extract (APFE) and Ranitidine in Experimental Rats. The APFE showed a significant effect on acid parameters and ulcer index in comparison with ulcer control rats. The higher dose of the flower extract $(500 \mathrm{mg} / \mathrm{kg})$ showed more superior effect when compared to the lower dose $(250 \mathrm{mg} / \mathrm{kg})$. The ulcer inhibition percentage was $52.8 \%$ and $71.7 \%$ in APFE at doses of 250 and $500 \mathrm{mg} / \mathrm{kg}$, respectively. Ranitidine, the standard drug, exhibited more ulcer inhibition percentage as compared to the flower extract (72.1\%) (Table 2/Figure 2).

3.3. Antiulcer Activity of DMSO Solution of the Date Palm Seed Extract (DPSE) and Ranitidine in Experimental Rats. The rats pretreated with the date seed extract and ranitidine demonstrated significant $(P<0.001)$ and dose-dependent reduction in acid parameters and ulcer index as compared 
TABLE 3: The ulcer protective effect of the date palm seed extract (DPSE) on the pylorus ligation-induced ulcer model in the experimental rat model.

\begin{tabular}{lcccccc}
\hline Treatment & Dose & Gastric volume $(\mathrm{ml})$ & $\mathrm{pH}$ & Total acidity $(\mathrm{mEq} / \mathrm{l})$ & Free acidity (mEq/l) & Ulcer index \\
\hline Control & $1 \mathrm{ml} / \mathrm{kg}$ & $8.47 \pm 0.15$ & $3.21 \pm 0.13$ & $120.83 \pm 2.20$ & $94.32 \pm 0.31$ & $3.58 \pm 0.09$ \\
& $250 \mathrm{mg} / \mathrm{kg}$ & $6.33 \pm 0.15^{*}$ & $2.7 \pm 0.08$ & $84.00 \pm 1.34^{*}$ & $74.33 \pm 1.73^{*}$ & $1.90 \pm 0.06^{*}$ \\
DPSE & $500 \mathrm{mg} / \mathrm{kg}$ & $5.40 \pm 0.10^{*}$ & $3.4 \pm 0.14$ & $75.67 \pm 1.38^{*}$ & $56.67 \pm 2.51^{*}$ & $1.48 \pm 0.10^{*}$ \\
& $50 \mathrm{mg} / \mathrm{kg}$ & $4.25 \pm 0.21^{*}$ & $5.35 \pm 0.15^{*}$ & $37.0 \pm 0.17^{*}$ & $17.0 \pm 0.24^{*}$ & $1.00 \pm 0.03^{*}$ \\
\hline
\end{tabular}

Control: rats received only distilled water; DPSE: rats received the date palm seed extract in a dose level (250 and $500 \mathrm{mg} / \mathrm{kg}$ ) (p.o.); ranitidine: rats received ranitidine which is dissolved in distilled water and given in a dose level $(50 \mathrm{mg} / \mathrm{kg})$ (p.o.) and served as a standard drug. $n=6 /$ group. Values are expressed as mean $\pm \operatorname{SEM}(n=6) .{ }^{*} P$ value is $<0.001$ versus control.

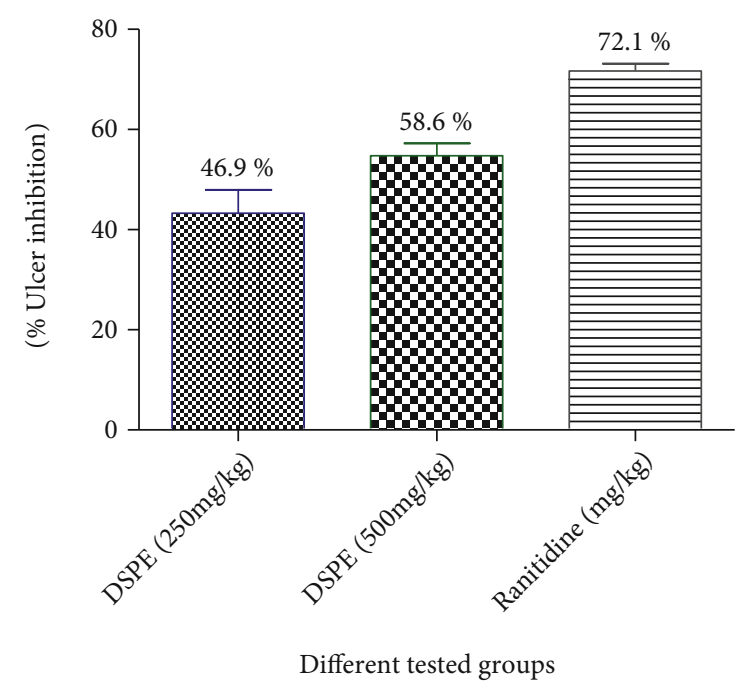

FIGURE 3: Effect of the date palm seed extract (DPSE) and ranitidine on the percentage of ulcer inhibition in the pylorus ligation-induced ulcer model in the experimental rat model. DPSE: rats received the date palm seed extract in a dose level (250 and $500 \mathrm{mg} / \mathrm{kg}$ ) (p.o.); ranitidine: rats received ranitidine which is dissolved in distilled water and given in a dose level $(50 \mathrm{mg} / \mathrm{kg})$ (p.o.) and served as a standard drug. $n=6 /$ group.

to the control ones. More ulcer protection was resulted in animals treated with ranitidine $(72.1 \%)$ when compared with the date seed group (46.9\% and 58.6\%) (Table $3 /$ Figure 3).

3.4. Antiulcer Activity of DMSO Solution of Oily Samples of the Date Palm Seed Extract and Ranitidine in Experimental Rats. Oral administrations of oily samples of the date seed extract either yellow or red demonstrated significant decreases in all estimated acid parameters and ulcer index as compared to the control. The antiulcerogenic effect of yellow or red oil on using dose $500 \mathrm{mg} / \mathrm{kg}$ was higher than that on using dose $250 \mathrm{mg} / \mathrm{kg}$. Red oil resulted in more decline in gastric volume and ulcer index as compared to yellow oil at a dose equal to $500 \mathrm{mg} / \mathrm{kg}$. The extracts exhibited gradual protections in ulcer as follows: red oil $(82 \%, 500 \mathrm{mg} / \mathrm{kg} ; 62 \%$, $250 \mathrm{mg} / \mathrm{kg}$ ) and yellow oil (55\%, $500 \mathrm{mg} / \mathrm{kg} ; 32 \%, 250 \mathrm{mg} /$ $\mathrm{kg}$ ). Ranitidine showed significant reduction when com- pared to the control $(P<0.001)$ and resulted in high ulcer inhibition percentage (72.1\%) (Table 4/Figure 4 ).

3.5. The Effects of DMSO Solution of the Different Extracts on the Macroscopic Finding of Gastric Ulcer in Experimental Rats. The gross findings in the control group revealed severe ulcer without perforation, while other treatment groups showed mild and moderate to minute ulcer which is noticed to decrease gradually and summarized in Table 5 .

3.6. The Effects of DMSO Solution of the Different Extracts on the Histological Findings of Gastric Tissue in Experimental Rats. Histological assessment of the gastric mucosa showed that pyloric ligation with the distal water oral group resulted in detachment of mucosal cells, congested blood vessels, and huge submucosal edema with lymphocytic infiltration as an inflammatory aggregate (Figures 5(a)-5(c)). Pretreatment with the different extracts considerably reduced these changes in the gastric mucosa and provided protection against gastric damage (Figures $5(\mathrm{~d})-5(\mathrm{f})$ ), besides significantly inhibiting the formation of these lesions' severity and restoring the mucosal damage as summarized in Table 6.

\section{Discussion}

Ulcer is a major gastrointestinal disease that affects $10 \%$ of the world population [22]. Pyloric ligation is the most common method for induction of gastric lesions in rats. These lesions are induced via stimulation of histamine-2 receptors (H2R) leading to hypersecretion of hydrochloric acid (HCL) inside the stomach, and this increases gastric acidity and changes gastric $\mathrm{pH}$ [23]. Pylorus ligation induced hyperacidity causing autodigestion of the gastric mucosa and breakdown of the gastric mucosal barrier which resulted as upper gastrointestinal damage including lesions, ulcers, and hemorrhage. This leads to accumulation of gastric acid and development of ulceration in the stomach. Histamine-2 receptor blockers are reported as the most common antiulcer drugs with effectiveness against the pyloric ligation model [24]. The agents that decrease gastric acid secretion and increase mucus secretion are effective in preventing the ulcers induced by this method like ranitidine, acting as an antiulcer agent by an antisecretory mechanism via 
TABLE 4: The ulcer protective effect of oily samples of the date palm seed extract on the pylorus ligation-induced ulcer model in the experimental rat model.

\begin{tabular}{|c|c|c|c|c|c|c|c|}
\hline \multirow[b]{2}{*}{ Treatment } & \multirow[b]{2}{*}{ Dose } & \multicolumn{6}{|c|}{ Parameters } \\
\hline & & $\begin{array}{l}\text { Gastric volume } \\
\qquad(\mathrm{ml})\end{array}$ & $\begin{array}{l}\text { Total acidity } \\
(\mathrm{mEq} / \mathrm{l})\end{array}$ & $\mathrm{pH}$ & $\begin{array}{l}\text { Free acidity } \\
(\mathrm{mEq} / \mathrm{l})\end{array}$ & Ulcer index & $\begin{array}{l}\% \text { of ulcer } \\
\text { inhibition }\end{array}$ \\
\hline Control & $1 \mathrm{ml} / \mathrm{kg}$ & $8.47 \pm 0.15$ & $120.83 \pm 2.20$ & $3.21 \pm 0.13$ & $94.32 \pm 0.31$ & $3.58 \pm 0.09$ & - \\
\hline \multirow{2}{*}{ Yellow oil } & $250 \mathrm{mg} / \mathrm{kg}$ & $2.55 \pm 0.11^{*}$ & $66.50 \pm 1.18^{*}$ & $1.8 \pm 0.05^{*}$ & $54.50 \pm 0.62^{*}$ & $2.43 \pm 0.05^{*}$ & $32.1 \%$ \\
\hline & $500 \mathrm{mg} / \mathrm{kg}$ & $2.38 \pm 0.12^{*}$ & $45.67 \pm 1.41^{*}$ & $2.2 \pm 0.7^{*}$ & $33.00 \pm 0.82^{*}$ & $1.61 \pm 0.12^{*}$ & $55.0 \%$ \\
\hline \multirow{2}{*}{ Red oil } & $250 \mathrm{mg} / \mathrm{kg}$ & $2.30 \pm 0.14^{*}$ & $76.33 \pm 2.03^{*}$ & $3.8 \pm 0.06^{*}$ & $58.83 \pm 1.01^{*}$ & $1.36 \pm 0.06^{\mathrm{a}}$ & $62.0 \%$ \\
\hline & $500 \mathrm{mg} / \mathrm{kg}$ & $1.60 \pm 0.11^{*}$ & $56.50 \pm 1.78^{*}$ & $4.8 \pm 0.07^{*}$ & $36.00 \pm 1.46^{*}$ & $0.62 \pm 0.05^{\mathrm{a}}$ & $82.7 \%$ \\
\hline Ranitidine & $50 \mathrm{mg} / \mathrm{kg}$ & $4.25 \pm 0.21^{*}$ & $37.0 \pm 0.17^{*}$ & $5.35 \pm 0.15^{*}$ & $17.0 \pm 0.24^{*}$ & $1.00 \pm 0.03^{*}$ & $72.1 \%$ \\
\hline
\end{tabular}

Control: rats received only distilled water; DPSE: rats received the date palm seed extract in a dose level (250 and $500 \mathrm{mg} / \mathrm{kg})$ (p.o.); ranitidine: rats received ranitidine which is dissolved in distilled water and given in a dose level $(50 \mathrm{mg} / \mathrm{kg}$ ) (p.o.) and served as a standard drug. $n=6 /$ group. Values are expressed as mean $\pm \operatorname{SEM}(n=6) .{ }^{\text {a }} P$ value is $<0.01$ and ${ }^{*} P$ value is $<0.001$ versus control.

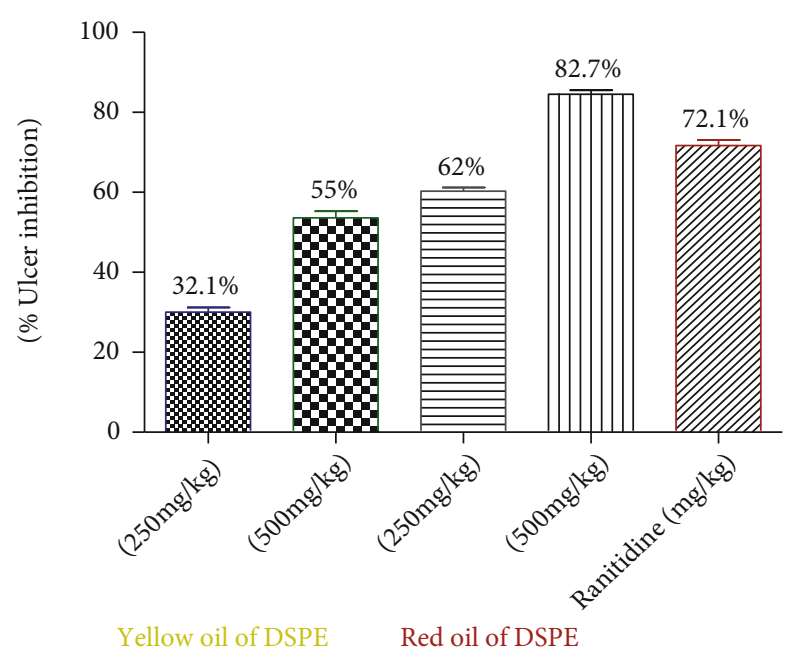

Different tested groups

FIGURE 4: Effect of oily samples of the date palm seed extract (DPSE) and ranitidine on the percentage of ulcer inhibition in the pylorus ligation-induced ulcer model in the experimental rat model. Yellow oil group: rats received date yellow oil in a dose level (250 and $500 \mathrm{mg} / \mathrm{kg}$ ) (p.o.); red oil group: rats received date red oil in a dose level (250 and $500 \mathrm{mg} / \mathrm{kg}$ ) (p.o.); ranitidine: rats received ranitidine which is dissolved in distilled water and given in a dose level ( $50 \mathrm{mg} / \mathrm{kg}$ ) (p.o.) and served as a standard drug. $n=6 /$ group.

inhibition of gastric secretion. The effective antiulcer agents are attributed to their antisecretory and antilesion actions as the main initiator of ulcer formation is overproduction of gastric acid that causes erosion of the gastric mucosa and damages the gastric protective barrier [25]. Several studies were conducted by using natural extracts or oils for controlling gastric ulcers induced by different experimental methods [25].

In this study, we used new, natural, safe, inexpensive, and available extracts and oils to be tested and evaluate their antiulcerogenic activity such as Aloe perryi and date palm extracts in addition to yellow oil and red oil and also to explore their protective activities against gastric ulcer induced by pyloric ligation in rats and compare their action with the standard known antiulcer drug ( $\mathrm{H} 2$ blocker such as ranitidine). A. perryi is a traditional herb with wide use in folklore medicine due to its safety and biological effectiveness $[26,27]$. The $A$. perryi extract has many pharmacological activities. Recent study showed that the $A$. perryi extract has anti-inflammatory action and cytotoxic activities [28]. Moreover, another in vivo study showed its antidiabetic action due to hypoglycemic and insulin-releasing effects and hepatic antioxidant potentials in STZ-induced diabetic rats [29] and alloxan-induced diabetic rats [30]. Also, recent in vitro study showed antidiabetic and antioxidant activities of Aloe species [31]. A. perryi flower extracts showed in vitro antiproliferative and anticancer activities in the liver, lung, colon, breast, prostate, and epithelial human cell lines [12]. In this study, we used $A$. perryi leaf and flower extracts to be tested in another pharmacological action in the gastric ulcer model induced by the pyloric ligation method and to investigate gastroprotective effects of the two extracts against ulcer induction and progression. Chemically, the A. perryi flower extract possesses various pharmacologically important compounds such as essential oils, alkaloids, amino acids, anthraquinone glycosides, glycoproteins, vitamins, minerals, and lectins [12]. On the other hand, the A. perryi leaf extract contains many classes of bioactive compounds including chromones, flavonoids, anthraquinones, anthrones, amino acids, lipids, carbohydrates, vitamins, and minerals [28]. Also, we used date seed oil which contains many bioactive ingredients with variant biological activities. The date seed is mainly composed of dietary fiber, protein, carbohydrates, and minerals (potassium, magnesium, calcium, phosphorus, sodium, and iron). Such substances perform several functions from a biological point of view, such as antioxidant, antibacterial, and antiviral activities. Date seeds are also a good source of oil (5 to $13 \%$ ), which is rich in phenolic compounds, tocopherols, and phytosterols [3, 6-9]. Date seed oil has been studied by other authors, and its composition of vitamins, minerals, and fatty acids makes it valuable for food formulations $[9,10]$. The literature data 
TABLE 5: Gross alteration scores for the gastric ulcer in control and treatment groups depending on mucosal color, hemorrhagic streaks, and deep or surface ulcer and perforation.

\begin{tabular}{|c|c|c|c|c|c|c|c|c|c|c|c|c|}
\hline \multirow{2}{*}{ Findings } & \multirow{2}{*}{ Control } & \multirow{2}{*}{ Ranitidine } & \multicolumn{2}{|c|}{ APLE } & \multicolumn{2}{|c|}{ APFE } & \multicolumn{2}{|c|}{ DPSE } & \multicolumn{2}{|c|}{ Yellow oil } & \multicolumn{2}{|c|}{ Red oil } \\
\hline & & & 250 & 500 & 250 & 500 & 250 & 500 & 250 & 500 & 250 & 500 \\
\hline Normal color & 0 & 3 & 0 & 0 & 0 & 3 & 0 & 1 & 0 & 0 & 1 & 3 \\
\hline Red color & 3 & 1 & 1 & 3 & 1 & 1 & 0 & 3 & 0 & 3 & 2 & 1 \\
\hline Hemorrhagic streak & 3 & 0 & 2 & 3 & 3 & 0 & 3 & 2 & 3 & 2 & 1 & 0 \\
\hline Superficial ulcer & 0 & 0 & 1 & 1 & 1 & 0 & 2 & 3 & & 3 & 1 & 0 \\
\hline Deep ulcer & 3 & 0 & 1 & 2 & 2 & 0 & 2 & 2 & 3 & 2 & 1 & 0 \\
\hline Perforation formation & 0 & 0 & 0 & 0 & 0 & 0 & 0 & 0 & 0 & 0 & 0 & 0 \\
\hline
\end{tabular}

Control: rats received only distilled water; APLE: rats received the Aloe perryi leaf extract in a dose level (500 mg/kg) (p.o.); ranitidine: rats received ranitidine which is dissolved in distilled water and given in a dose level $(50 \mathrm{mg} / \mathrm{kg}$ ) (p.o.) and served as a standard drug; APFE: rats received the Aloe perryi flower extract in a dose level (500 mg/kg) (p.o.); DPSE: rats received the date palm seed extract in a dose level (500 mg/kg) (p.o.); yellow oil group: rats received date yellow oil in a dose level $(500 \mathrm{mg} / \mathrm{kg}$ ) (p.o.); red oil group: rats received date red oil in a dose level $(500 \mathrm{mg} / \mathrm{kg}$ ) (p.o.). Gross severity scores: $0=$ no changes, $1=$ mild or focal, $2=$ mild to moderate, and $3=$ severe.

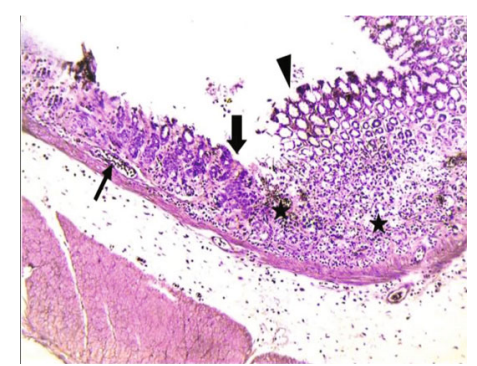

(a)

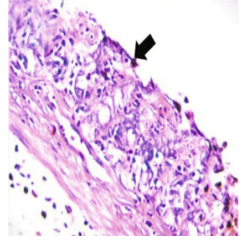

(b)

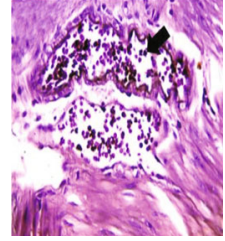

(c)

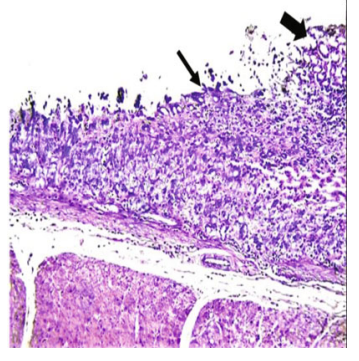

(d)

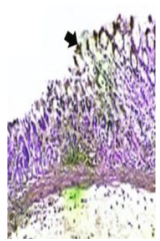

(e)

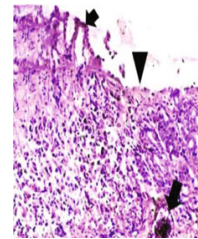

(f)

FIGURE 5: Representative photomicrographs showing H\&E-stained rat gastric sections. H\&E-stained gastric sections revealed normal mucosal parts (arrowhead) followed by denuded part and remnant glands (thick arrow) without mucosal cells covered, congested blood vessels (thin arrow), and huge submucosal edema with lymphocytic infiltration and inflammatory aggregates (stars) ( $\times 100 \mathrm{magnification)}$ (a). High magnification of the ulcerative surface with disruption and complete losses of all mucosal covered epithelium (gastric pits) and still low parts of the glandular layer which mixed with erythrocytes and individual inflammatory cells and/or destructed necrotic cells and congested deep blood vessels (arrow) (400x magnification in the control group) (b, c). Representative of the restoration of the mucosal structure (thick arrow) with still denuded and inflammatory cells individually between gastric glands (thin arrow) (100x magnification: amelioration findings in each APLE $250 \mathrm{mg} / \mathrm{kg}$ and DSPE $250 \mathrm{mg} / \mathrm{kg}$ group) (d). Representative of the restoration of mucosal surface structure with still minute ulceration surface (arrowhead) with mucosal necrosis and inflammatory cell aggregations (star) beside engorged blood vessels (thin arrow) (100x magnification: amelioration findings in each red oil DPSE $250 \mathrm{mg} / \mathrm{kg}$, yellow oil DPSE, DSPE $500 \mathrm{mg} / \mathrm{kg}$, APFE $500 \mathrm{mg} / \mathrm{kg}$, and APLE $500 \mathrm{mg} / \mathrm{kg}$ ) (f). Remodeling of all gastric structure layers with prominent normal gastric mucosa (100x magnification: amelioration findings in each red oil DPSE $500 \mathrm{mg} / \mathrm{kg}$, ranitidine, and APFE $500 \mathrm{mg} / \mathrm{kg}$ group) (e).

confirm that date seed oil is an interesting source of important nutrients that have a very positive effect on human health [32].

Our results showed that pyloric ligation for 6 hours led to marked significant increases in total and free acidity, ulcer index, and hyperacidity of gastric content and decreased $\mathrm{pH}$ to being acidic, indicating the severity of this induction model of gastric ulcer. Moreover, histopathological study was performed that showed in macroscopic evaluation of gastric ulcer a deeply formed ulcer in the pyloric ligation 
TABLE 6: Histological lesion scores for gastric alterations depending on loss of the mucosal and glandular layers, edema, and congested blood vessels with control and treatment doses and types.

\begin{tabular}{|c|c|c|c|c|c|c|c|c|c|c|c|c|}
\hline \multirow{2}{*}{ Lesion } & \multirow{2}{*}{ Control } & \multirow{2}{*}{ Ranitidine } & \multicolumn{2}{|c|}{ APLE } & \multicolumn{2}{|c|}{ APFE } & \multicolumn{2}{|c|}{ DPSE } & \multicolumn{2}{|c|}{ Yellow oil } & \multicolumn{2}{|c|}{ Red oil } \\
\hline & & & 250 & 500 & 250 & 500 & 250 & 500 & 250 & 500 & 250 & 500 \\
\hline Denudation of the mucosal parts & 3 & 1 & 3 & 2 & 0.5 & 2 & 3 & 2 & 3 & 2 & 2 & 0 \\
\hline Congested blood vessels & 3 & 0 & 3 & 1 & 1 & 1 & 3 & 1 & 3 & 1 & 1 & 0 \\
\hline Inflammatory cell infiltrations & 3 & 0 & 2 & 1 & 2 & 1 & 2 & 1 & 2 & 1 & 1 & 0 \\
\hline Loss of the mucosal and glandular layers & 3 & 0.5 & 3 & 2 & 1 & 2 & 3 & 2 & 3 & 2 & 2 & 0 \\
\hline Mucosal and/or submucosal edema & 3 & 1 & 3 & 2 & 2 & 2 & 3 & 1 & 2 & 2 & 2 & 0 \\
\hline Regenerated tissues & 0 & 2 & 1 & 2 & 1 & 2 & 1 & 1 & 0 & 1 & 1 & 3 \\
\hline Return to nearly normal feature & 0 & 2 & 0 & 0 & 0 & 0 & 0 & 0 & 0 & 0 & 0 & 3 \\
\hline
\end{tabular}

Control: rats received only distilled water; APLE: rats received the Aloe perryi leaf extract in a dose level (500 mg/kg) (p.o.); ranitidine: rats received ranitidine which is dissolved in distilled water and given in a dose level $(50 \mathrm{mg} / \mathrm{kg}$ ) (p.o.) and served as a standard drug; APFE: rats received the Aloe perryi flower extract in a dose level $(500 \mathrm{mg} / \mathrm{kg}$ ) (p.o.); DPSE: rats received the date palm seed extract in a dose level $(500 \mathrm{mg} / \mathrm{kg})$ (p.o.); yellow oil group: rats received date yellow oil in a dose level $(500 \mathrm{mg} / \mathrm{kg}$ ) (p.o.); red oil group: rats received date red oil in a dose level $(500 \mathrm{mg} / \mathrm{kg})$ (p.o.). The lesion scores: $0=$ normal appearance; $0.5=$ mild changes; 1 = moderate changes; $1.5=$ severe changes; 2 = over severity; and $3=$ diffused.

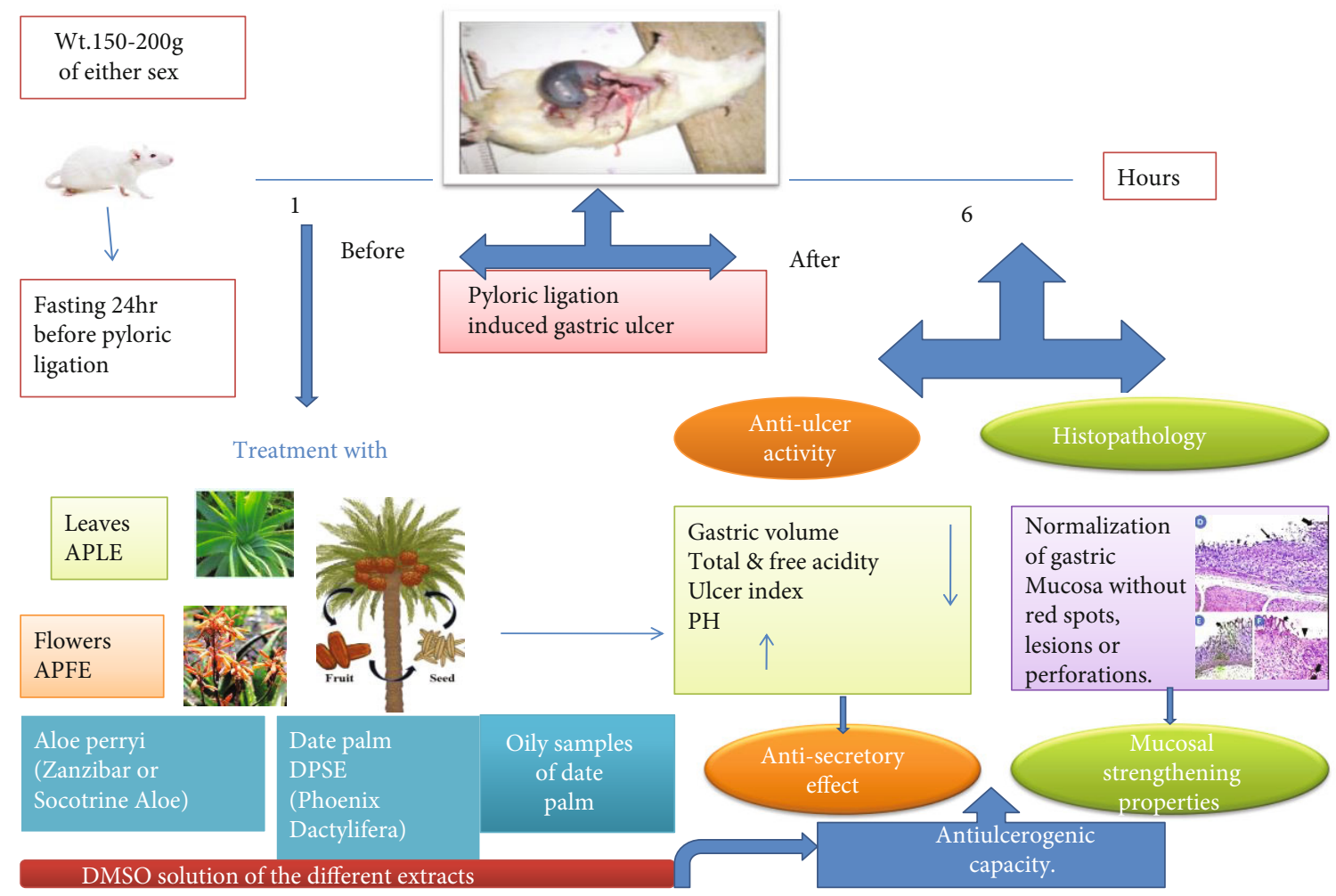

FIGURE 6: Schematic diagram illustrating antiulcer activities of Aloe perryi and date palm extracts in addition to yellow oil and red oil in the pyloric ligation-induced gastric ulcer model.

method. The abovementioned changes indicated gastric ulcer formation by the pyloric ligation technique, and these observations were in accordance with previous studies' results $[33,34]$.

On the other hand, pretreatment with $A$. perryi and date palm extracts in addition to yellow and red oils for 1 hour before pyloric ligation has a protective effect against gastric ulcer progression which is confirmed by significant reduction of hyperacidity, total and free acidity, and ulcer index. Macroscopic evaluation of gastric ulcer showed normalization of the gastric mucosa without red spots, lesions, or perforations. These results showed the promising gastroprotective effects of $A$. perryi and date palm extracts in addition to yellow oil and red oil against the pyloric ligation ulcer model. These agents can be involved in gastric ulcer management. 


\section{Conclusion}

Collectively, our findings demonstrated novel antiulcer activities of Aloe perryi and date palm extracts in addition to yellow oil and red oil in the pyloric ligation-induced gastric ulcer model as a result of antisecretory and mucosal strengthening properties. This is a preliminary study that may be a promising strategy to ameliorate the gastric ulcer associated with pyloric ligation, but further investigations are required to fully understand the action mechanisms of the extracts (Figure 6).

\section{Data Availability}

All current results of this work are available with the corresponding author and can be provided upon reasonable request.

\section{Conflicts of Interest}

The authors declare that they have no competing interests.

\section{References}

[1] L. Kuna, J. Jakab, R. Smolic, N. Raguz-Lucic, A. Vcev, and M. Smolic, "Peptic ulcer disease: a brief review of conventional therapy and herbal treatment options," Journal of Clinical Medicine, vol. 8, no. 2, p. 179, 2019.

[2] A. Lanas and F. K. Chan, "Peptic ulcer disease," The Lancet, vol. 390, no. 10094, pp. 613-624, 2017.

[3] E. Stern, K. Sugumar, and J. D. Journey, "Peptic ulcer perforated," in StatPearls, StatPearls Publishing;, Treasure Island (FL), 2021, https://www.ncbi.nlm.nih.gov/books/ NBK538326/.

[4] M. K. Prasad, M. Kumar, S. Sukanta, A. Nadeem, R. Matiur, and C. B. Choudhary, "Comparative study of methanolic extract of banana, ranitidine and omeprazole on total acid secretion and gastric ulcer healing effect in albino rats," International Journal of Contemporary Medical Research, vol. 7, no. 2, 2020.

[5] K. S. Patil, R. Kenia, and S. Chaturvedi, "Anti-ulcer activity of stem bark of Shorea tumbuggaia," Journal of Natural Remedies, vol. 4, no. 1, pp. 36-40, 2004.

[6] M. Bhatnagar and S. Sisodia, "Antisecretory and antiulcer activity ofAsparagus racemosusWilld. against indomethacin plus pyloric ligation-induced gastric ulcer in rats," Journal of Herbal Pharmacotherapy, vol. 6, no. 1, pp. 13-20, 2006.

[7] P. Malairajan, G. Gopalakrishnan, S. Narasimhan, and K. J. Veni, "Evalution of anti-ulcer activity of Polyalthia longifolia (Sonn.) Thwaites in experimental animals," Indian Journal of Pharmacology, vol. 40, no. 3, pp. 126-128, 2008.

[8] Y. E. Yismaw, M. Abdelwuhab, D. B. Ambikar, A. E. Yismaw, D. Derebe, and W. Melkam, "Phytochemical and antiulcer activity screening of seed extract of Cordia africana Lam (Boraginaceae) in pyloric ligated rats," Clinical Pharmacology: Advances and Applications, vol. 12, pp. 67-73, 2020.

[9] A. Bhardwaj, R. Kumar, V. Dabasa, and N. Alam, "Evaluation of anti-ulcer activity of Citrullus lanatus seed extract in Wistar albino rats," International Journal of Pharmacy and Pharmaceutical Sciences, vol. 4, no. 5, pp. 135-139, 2012.
[10] M. R. Sravani and A. Naveen, "Anti-ulcer effect of sodium cromoglycate in NSAID and ethanol induced ulcer in comparison with ranitidine in rats," The Pharma Innovation, vol. 6, no. 8, Part A, p. 1, 2017.

[11] H. Ardalani, A. Hadipanah, and A. Sahebkar, "Medicinal plants in the treatment of peptic ulcer disease: a review," Mini Reviews in Medicinal Chemistry, vol. 20, no. 8, pp. 662-702, 2020.

[12] M. M. Al-oqail, A. El-Shaibany, E. Al-Jassas, E. S. Al-Sheddi, S. M. Al-Massarani, and N. N. Farshori, "In vitro antiproliferative activities of Aloe perryi flowers extract on human liver, colon, breast, lung, prostate and epithelial cancer cell lines," Pakistan Journal of Pharmaceutical Sciences, vol. 29, Supplement 2, pp. 723-729, 2016.

[13] N. A. Ali, W. D. Jülich, C. Kusnick, and U. Lindequist, "Screening of Yemeni medicinal plants for antibacterial and cytotoxic activities," Journal of Ethnopharmacology, vol. 74, no. 2, pp. 173-179, 2001.

[14] R. A. Mothana, N. al-Musayeib, A. Matheeussen, P. Cos, and L. Maes, "Assessment of the in vitro antiprotozoal and cytotoxic potential of 20 selected medicinal plants from the island of Soqotra," Molecules, vol. 17, no. 12, pp. 14349-14360, 2012.

[15] S. H. Orabi and S. M. Shawky, "Effect of date palm (Phoenix dactylifera) seeds extracts on hematological, biochemical parameters and some fertility indices in male rats," International Journal of Sciences: Basic and Applied Research, vol. 17, no. 1, pp. 137-147, 2014.

[16] D. Khezerloo, T. Mortezazadeh, B. Farhood, P. Sheikhzadeh, N. Seyfizadeh, and L. Pezhman, "The effect of date palm seed extract as a new potential radioprotector in gammairradiated mice," Journal of Cancer Research and Therapeutics, vol. 15, no. 3, pp. 517-521, 2019.

[17] E. Koffi, T. Sea, Y. Dodehe, and S. Soro, "Effect of solvent type on extraction of polyphenols from twenty three Ivorian plants," Journal of Animal and Plant Sciences, vol. 5, no. 3, pp. 550-558, 2010.

[18] M. A. Ali, T. A. Al-Hattab, and I. A. Al-Hydary, "Extraction of date palm seed oil (Phoenix dactylifera) by soxhlet apparatus," International Journal of Advances in Engineering \& Technology, vol. 8, no. 3, pp. 261-271, 2015.

[19] H. Shay, "A simple method for the uniform production of gastric ulceration in the rat," Gastroenterology, vol. 5, pp. 43-45, 1945.

[20] V. P. Reddy, G. Sudheshna, S. K. Afsarf et al., "Evaluation of anti-ulcer activity of Citrullus colocynthis fruit against pylorus ligation induced ulcers in male wistar rats," International Journal of Pharmacy and Pharmaceutical Sciences, vol. 4, no. 2, pp. 446-451, 2012.

[21] K. S. Suvarna, C. Layton, and J. D. Bancroft, "Bancroft's Theory and Practice of Histological Techniques E-Book," in Elsevier Health Sciences, Elsevier, 2018.

[22] G. Arumugam and S. Panneerselvam, "A biochemical study on the gastroprotective effect of hydroalcoholic extract of Andrographis paniculata in rats," Indian Journal of Pharmacology, vol. 43, no. 4, pp. 402-408, 2011.

[23] S. Zaghlool, B. A. Shehata, A. A. Abo-Seif, and H. A. El-Latif, "Comparison between the protective effects of famotidine, ginger and marshmallow on pyloric ligation-induced peptic ulcer in rats," Journal of Bioequivalence \& Bioavailability, vol. 7, no. 4, pp. 170-178, 2015.

[24] S. Okabe, K. Takeuchi, M. Okada, Y. Kumadaki, M. Nakata, and H. Nakata, "Effects of nizatidine, a new histamine H2- 
receptor antagonist, on gastric acid secretion and various gastric and duodenal lesions in rats: comparison with cimetidine," Nihon Yakurigaku Zasshi, vol. 93, no. 3, pp. 133-144, 1989.

[25] I. Khémiri and L. Bitri, "Effectiveness of Opuntia ficus indica L. inermis seed oil in the protection and the healing of experimentally induced gastric mucosa ulcer," Oxidative Medicine and Cellular Longevity, vol. 2019, Article ID 1568720, 17 pages, 2019.

[26] Haller JS Jr, "A drug for all seasons. Medical and pharmacological history of aloe," Bulletin of the New York Academy of Medicine, vol. 66, no. 6, pp. 647-659, 1990.

[27] M. al-Sobarry, A. Alwashli, Y. Cherrah, and K. Alaoui, “Toxicité aiguë et action analgésique d'extrait éthanolique des feuilles d'Aloe perryi, plante endémique du Yémen," Phytothérapie, vol. 11, no. 1, pp. 17-21, 2013.

[28] R. S. Suliman, S. S. Alghamdi, R. Ali et al., "Metabolites profiling, in vitro, in vivo, computational pharmacokinetics and biological predictions of Aloe perryi resins methanolic extract," Plants, vol. 10, no. 6, p. 1106, 2021

[29] T. S. Aldayel, G. M. Alshammari, U. M. Omar, M. H. Grace, M. A. Lila, and M. A. Yahya, "Hypoglycaemic, insulin releasing, and hepatoprotective effect of the aqueous extract ofAloe perryiBaker resin (Socotran aloe) in streptozotocin-induced diabetic rats," Journal of Taibah University for Science, vol. 14, no. 1, pp. 1671-1685, 2020.

[30] I. CO and C. PC, "Hypoglycemic properties of ethanolic extracts of Gongronema latifolium, Aloe perryi, Viscum album and Allium sativum administered to alloxan-induced diabetic albino rats (Rattus norvegicus)," Pharmacognosy Communications, vol. 3, no. 2, pp. 12-16, 2013.

[31] T. S. Aldayel, M. H. Grace, M. A. Lila, M. A. Yahya, U. M. Omar, and G. Alshammary, "LC-MS characterization of bioactive metabolites from two Yemeni aloe spp. with antioxidant and antidiabetic properties," Arabian Journal of Chemistry, vol. 13, no. 4, pp. 5040-5049, 2020.

[32] A. Mrabet, A. Jiménez-Araujo, A. Guillén-Bejarano, R. Rodríguez-Arcos, and M. Sindic, "Date seeds: a promising source of oil with functional properties," Foods, vol. 9, no. 6, p. 787,2020

[33] S. L. Zhang, H. Li, X. He et al., "Alkaloids from Mahonia bealei posses anti- $\mathrm{H}^{+} / \mathrm{K}^{+}$-ATPase and anti-gastrin effects on pyloric ligation-induced gastric ulcer in rats," Phytomedicine, vol. 21, no. 11, pp. 1356-1363, 2014.

[34] A. N. Patil, S. N. Mali, S. B. Raut, M. G. Advani, and S. Pawar, "Evaluation of anti-ulcer effect of amlodipine in gastric ulcer models in rats," Indian Journal of Pharmacology, vol. 44, no. 3, pp. 387-389, 2012. 